\title{
BAMS A
}

\section{Tracking Air-Sea Exchange and Upper-Ocean Variability in the Indonesian-Australian Basin during the Onset of the 2018/19 Australian Summer Monsoon}

Ming Feng, Yongliang Duan, Susan Wijffels, Je-Yuan Hsu, Chao Li, Huiwu Wang, Yang Yang, Hong Shen, Jianjun Liu, Chunlin Ning, and Weidong Yu

\begin{abstract}
Sea surface temperatures (SSTs) north of Australia in the Indonesian-Australian Basin are significantly influenced by Madden-Julian oscillation (MJO), an eastward-moving atmospheric disturbance that traverses the globe in the tropics. The region also has large-amplitude diurnal SST variations, which may influence the air-sea heat and moisture fluxes, that provide feedback to the MJO evolution. During the 2018/19 austral summer, a field campaign aiming to better understand the influences of air-sea coupling on the MJO was conducted north of Australia in the Indonesian-Australian Basin. Surface meteorology from buoy observations and upper-ocean data from autonomous fast-profiling float observations were collected. Two MJO convective phases propagated eastward across the region in mid-December 2018 and late January 2019 and the second MJO was in conjunction with a tropical cyclone development. Observations showed that SST in the region was rather sensitive to the MJO forcing. Air-sea heat fluxes warmed the SST throughout the $2018 / 19$ austral summer, punctuated by the MJO activities, with a $2^{\circ}-3^{\circ} \mathrm{C}$ drop in SST during the two MJO events. Substantial diurnal SST variations during the suppressed phases of the MJOs were observed, and the near-surface thermal stratifications provided positive feedback for the peak diurnal SST amplitude, which may be a mechanism to influence the MJO evolution. Compared to traditionally vessel-based observation programs, we have relied on fast-profiling floats as the main vehicle in measuring the upper-ocean variability from diurnal to the MJO time scales, which may pave the way for using cost-effective technology in similar process studies.
\end{abstract}

https://doi.org/10.1175/BAMS-D-19-0278.1

Corresponding author: Ming Feng, ming.feng@csiro.au

Supplemental material: https://doi.org/10.1175/BAMS-D-19-0278.2

In final form 20 March 2020

(02020 American Meteorological Society

For information regarding reuse of this content and general copyright information, consult the AMS Copyright Policy.

(c) (i) This article is licensed under a Creative Commons Attribution 4.0 license. 
AFFILIATIONS: Feng and Hsu-Oceans and Atmosphere, CSIRO, Crawley, Western Australia, and Centre for Southern Hemisphere Oceans Research, Hobart, Tasmania, Australia; Duan, Li, Wang, Yang, Shen, Liu, and Ning-First Institute of Oceanography, and Laboratory for Regional Oceanography and Numerical Modeling, Qingdao National Laboratory for Marine Science and Technology, Qingdao, China; WijffelsOceans and Atmosphere, CSIRO, Crawley, Western Australia, and Centre for Southern Hemisphere Oceans Research, Hobart, Tasmania, Australia, and Woods Hole Oceanographic Institution, Woods Hole, Massachusetts; Yu-Laboratory for Regional Oceanography and Numerical Modeling, Qingdao National Laboratory for Marine Science and Technology, Qingdao, and School of Atmospheric Sciences, Sun Yat-Sen University, and Southern Marine Science and Engineering Guangdong Laboratory, Zhuhai, and Guangdong Province Key Laboratory for Climate Change and Natural Disaster Studies, Sun Yat-Sen University, Guangzhou, China

$\mathrm{T}$ he Madden-Julian oscillation (MJO) is an eastward-moving disturbance of clouds, rainfall, winds, and pressure that traverses the globe in the tropics with a period in the range of 30-80 days. The MJO is the dominant mode of intraseasonal variability in the tropical Indo-Pacific warm pool (Zhang 2005). It modulates the timing and strength of monsoons and is an important influence for the development of some high-impact weather events such as tropical cyclones, flood, and drought in the Indo-Pacific region. The MJO offers promising perspectives to forecast tropical rainfall with a lead time of a couple of weeks; however, current state-of-art weather forecasting models have systematic biases and cannot reproduce the MJO well (e.g., Kim et al. 2014), possibly because they do not represent air-sea interaction processes associated with the MJO (DeMott et al. 2015).

During boreal summer, intraseasonal oscillations display prominent northwardnortheastward propagation and variability, extending much farther from the equator compared to the MJOs in austral summer and interacting with summer Asian monsoons (Wang and Xie 1997; Lee et al. 2013). After boreal summer, the first eastward-propagating MJO is often associated with the onset of the Australian monsoon (Hashiguchi et al. 1995; Duan et al. 2019), which normally takes place in early December (Kajikawa et al. 2010). The MJOs can also modulate the Australian monsoon rainfall and winds on intraseasonal time scales (Wheeler and Hendon 2004).

The strongest large-scale intraseasonal sea surface temperature (SST) variations in austral summer in the tropics are found north of Australia in the Indonesian-Australian Basin, forced by air-sea heat flux and wind-driven current anomalies associated with the MJO (Vialard et al. 2013; Marshall and Hendon 2014). In addition, large diurnal variation of SST (DV SST) has been modeled and observed in the region (Seo et al. 2014; Wang and Zhang 2017). The air-sea coupling at these two time scales can have significant influences on the MJO and its forecasts (DeMott et al. 2015), which has motivated a number of observation programs in the Indian Ocean: the Mirai Indian Ocean Cruise for the Study of the MJO (MISMO; Yoneyama et al. 2008), the air-sea interactions at several time scales in the Indian Ocean (Cirene; Vialard et al. 2009), Cooperative Indian Ocean Experiment on Intraseasonal Variability/Dynamics of the Madden-Julian Oscillation (CINDY-DYNAMO; Yoneyama et al. 2013; Moum et al. 2014), and Ocean Mixing and Monsoon/Air-Sea Interactions in the Northern Indian Ocean Regional Initiative (OMM-ASIRI; Wijesekera et al. 2016), mostly focused on the equatorial central Indian Ocean. Both observation and model studies show that the increase of daily mean SST can enhance the latent and sensible heat fluxes into the atmosphere, providing important feedbacks to the evolution of the MJO (Seo et al. 2014; Moum et al. 2014). Regional oceanography and changes of diurnal thermocline can affect the magnitude of diurnal SST variations nonlinearly, thus, exploring the diurnal variation of vertical mixing in the upper ocean is also critical to improve the MJO forecasting. 
The Maritime Continent, a unique mixture of land and ocean straddling the equator between the Indian and Pacific Oceans, has been identified as a barrier/weakening mechanism for the eastward propagation of the MJOs by inhibiting convection development over the sea (Zhang and Ling 2017). There has been suggestion that warm SST anomalies in the Indonesian-Australian Basin, to the south of the Maritime Continent, may draw the MJO southward before reaching the Maritime Continent through air-sea interactions (Zhou and Murtugudde 2020). However, air-sea exchanges in the region during the MJO evolution has not been examined previously from field observations.

In November 2018, a field campaign was carried out in the region, under a bilateral collaboration between the Centre for Southern Hemisphere Oceans Research (CSHOR; CSHOR 2018), CSIRO, Australia, and the First Institute of Oceanography (FIO), Ministry of Natural Resources, China. This field campaign is also under the umbrella of the Years of the Maritime Continent (YMC) program during 2017-20 (www.jamstec.go.jp/ymc/). The goal of the YMC is to improve the understanding and prediction of local multiscale variability of the Maritime Continent weather-climate system and its global impact through observation and modeling.

In our campaign, one surface meteorology and ocean profiling buoy from the FIO, and eight profiling floats from CSHOR were deployed to the north of Australia, in a region that experiences relatively large MJO and diurnal SST variations (e.g., Duvel and Vialard 2007). The region also has large uncertainties in air-sea heat fluxes among different atmosphere reanalysis products (Yu et al. 2007; Hermes et al. 2019). For almost a decade, the site has been proposed as a high-priority extension of the tropical mooring array of the Indian Ocean [Research Moored Array for African-Asian-Australian Monsoon Analysis and Prediction (RAMA); McPhaden et al. 2009]. The region will become a future focus of the Indian Ocean Observing System to improve the MJO and monsoon forecasting systems and a RAMA flux reference site has been reintroduced [Indian Ocean Observing System (IndOOS); Beal et al. 2019].

The aim of the field campaign is to obtain new insights into air-sea coupling in the Indonesian-Australian Basin using fast ocean profiling platforms to resolve the very nearsurface ocean temperature structures, as well as the key atmospheric variables such as humidity, air temperature, vector winds, and radiation parameters; such measurements in the region are unprecedented, to assess the upper-ocean response to the MJO forcing in the Indonesian-Australian Basin as compared to other regions in the Indian Ocean. The data will be used to understand the coupled model performance in capturing the scale, strength, and atmospheric signature of the MJO and diurnal warming events and to improve model parameterizations for the simulation of upper-ocean processes on these time scales. The data can also be used to better understand oceanography processes during the transition between the Australian monsoon and the trade wind regimes. This paper reviews the field campaign and highlights some key research results to be delivered under the CSHOR-FIO collaboration.

\section{Design of the campaign}

Buoy and profiling float measurements. A miniature version of the Bailong buoy system from the FIO (Cole et al. 2011) was used in the program (SB1), which has a surface meteorological package to measure the surface air temperature, humidity, pressure, winds, and shortwave and longwave radiation at a 10-min interval, and a subsurface (within the upper $500 \mathrm{~m}$ ) oceanographic package to measure upper-ocean temperature, salinity, pressure, oxygen, and current speed and direction at a 30-min interval. The details of the instrumentation are listed in Tables ES1 and ES2. We chartered an offshore support vessel, Limitless, from the Offshore Unlimited Pty. Ltd. for the period of 19-24 November 2018 to deploy the buoy and the profiling platforms. After a regional bathymetry survey on 20 November, the buoy system was deployed on 21 November at $16^{\circ} 51.432^{\prime} \mathrm{S}, 115^{\circ} 13.314^{\prime} \mathrm{E}$, on a plateau about 300 nautical miles $(\sim 555 \mathrm{~km})$ north of Exmouth, Western Australia, just outside of the border of the Australian Exclusive 
Economic Zone (Fig. 1, Fig. $\mathrm{SB} 1)$. The real-time data from the buoy were transmitted to the FIO laboratory every 10 min via satellites.

On 22 November, six Air Launched Autonomous Micro Observer (ALAMO) profiling floats (Jayne and Bogue 2017) from MRV Systems [one with SBE-41 conductivitytemperature-depth (CTD) sensor and five with RBR CTD sensors], and two Electromagnetic Autonomous Profiling Explorer (EM-APEX) floats were deployed near the buoy, at a radius of approximately $5 \mathrm{~km}$. Two ALAMO floats failed within 2 days of deployment. The ALAMO floats profiled the temperature and salinity only during ascending phase, and the EM-APEX floats profiled temperature, salinity and current velocity during both ascending and descending phases (Sanford et al. 2005; Hsu et al. 2017). The vertical resolution of ALAMO float measurements using the RBR sensors was $0.1 \mathrm{~m}$ in the upper $5 \mathrm{~m}$ and $1 \mathrm{~m}$ down to $20 \mathrm{~m}$, and that using the Seabird sensors was $1 \mathrm{~m}$ in the upper $20 \mathrm{~m}$. The RBR CTD sensors allow temperature and salinity measurements within a few centimeters below the sea surface. The vertical resolution of EM-APEX float measurements was about $3.5 \mathrm{~m}$ (Sanford et al. 2011). The nominal temporal resolution between profiles on ALAMO floats and EM-APEX floats was about $3 \mathrm{~h}$ and $30 \mathrm{~min}$, respectively.

Other datasets used in the study. Several other datasets are used to help interpret atmosphere and ocean processes during the field experiment. The NOAA extended reconstructed SST v5 is used to identify SST anomalies in the Indo-Pacific Ocean, as infrared

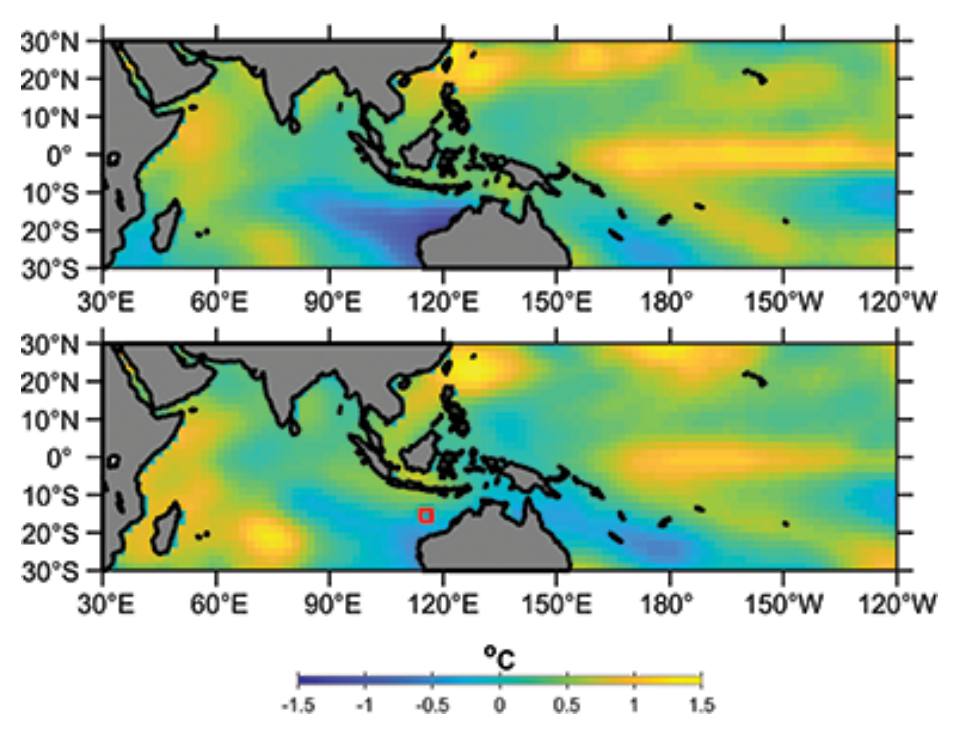

Fig. 1. Sea surface temperature anomalies in the Indo-Pacific Ocean during (top) December 2018 and (bottom) January 2019. The red box in the bottom panel in the IndonesianAustralian Basin denotes the field survey region. 
SST measurements may significantly underestimate the SST cooling under convective systems (e.g., Duvel and Vialard 2007). The propagation of MJO convection ("General conditions during the campaign" section) is identified using daily outgoing longwave radiation (OLR) data from NOAA and precipitation data from the near-real-time legacy product of Tropical Rainfall Measuring Mission (TRMM) Multisatellite Precipitation Analysis (3B42RT), version 7 (Huffman and Bolvin 2018). The measurements of SST from Himawari-8 satellite and sea surface height anomalies (SSHA) from Integrated Marine Observing System (IMOS) data portal (http://imos.aodn.org.au /webportal) are used to compare with the float measurements ("Featured research studies in the experiment" section). More details of these datasets are described in the online supplementary text (https://doi .org/10.1175/BAMS-D-19-0278.2).

\section{General conditions during the campaign}

The global ocean was under the influence of a weak El Niño event in 2018/19 austral summer. Cool SST anomalies of up to $-1.5^{\circ} \mathrm{C}$ were observed in the southeast Indian Ocean and the Indonesian-Australian Basin, whereas the central equatorial Pacific and the western Indian Ocean experienced warmer than usual conditions (Fig. 1, Fig. SB2). The cool SST anomalies in the southeast Indian Ocean started to fade around January 2019. The evolution of SST anomalies is consistent with a composite analysis of El Niño influences in the region (Zhang et al. 2017), that is, SST in the region is typically cooler (warmer) than normal by $\sim 0.2^{\circ} \mathrm{C}$ $\left(\sim 0.5^{\circ} \mathrm{C}\right)$ before (after) an El Niño peak.

The intraseasonal SST and OLR anomalies north of Australia have standard deviations of about $0.4^{\circ} \mathrm{C}$ and

\section{Sea surface temperature variability in the Indonesian-Australian Basin and El Niño}

Intense SST variability exists in the region to the north of Australia. Warm SSTs are usually observed during and after the peak of an El Niño event in austral summer, such as during the 1997/98 and 2015/16 events (Fig. SB2), due to increased solar radiation and reduced latent heat release (Zhang et al. 2017). During the evolution of some of the El Niño events, SSTs are cooler than normal before the El Niño peak.
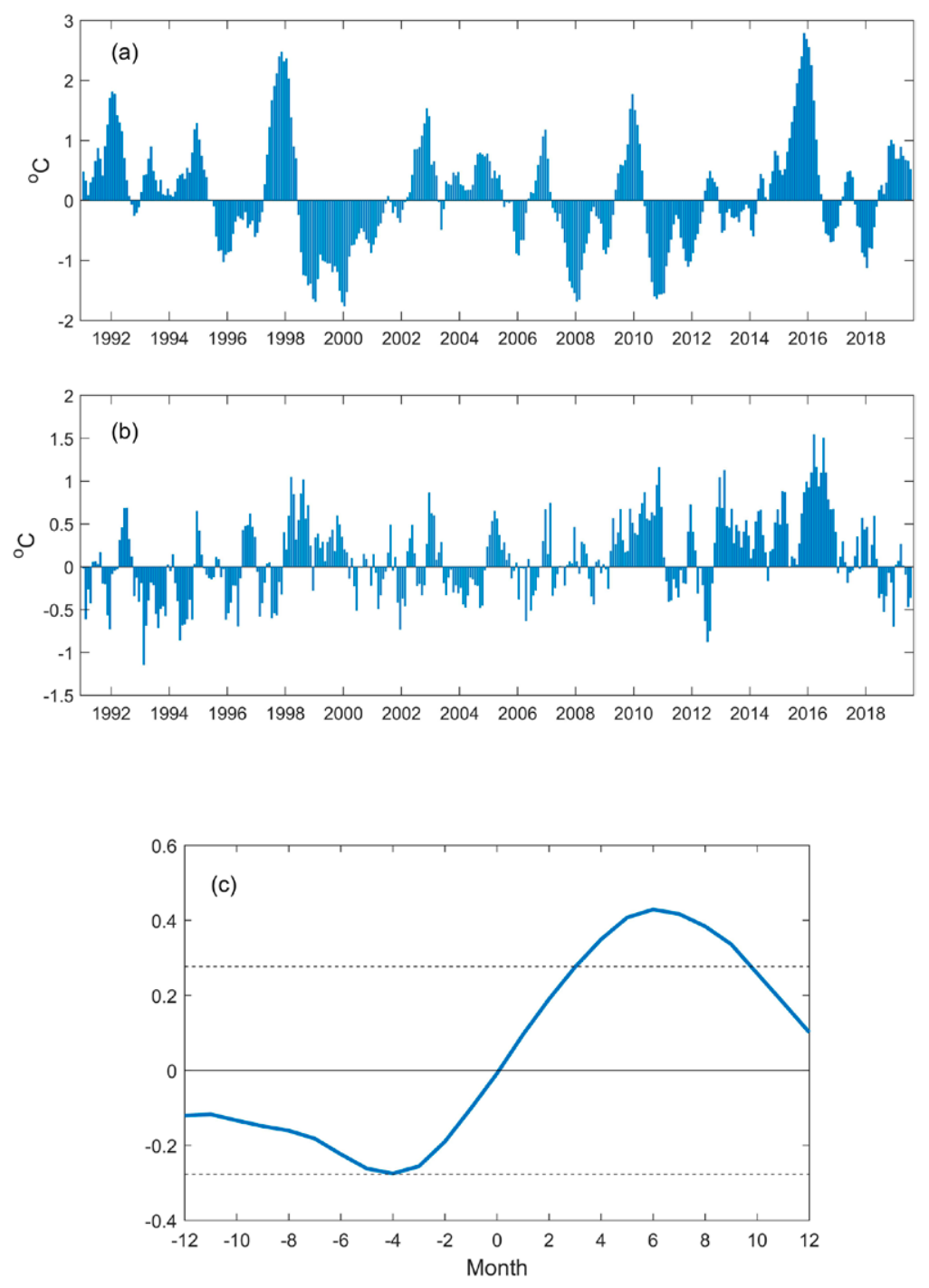

Fig. SB2. Monthly SST anomalies (a) in the Niño-3.4 region $\left(5^{\circ} \mathrm{S}-5^{\circ} \mathrm{N}, 170^{\circ}-120^{\circ} \mathrm{W}\right)$ and (b) off northern Australia $\left(18^{\circ}-10^{\circ} \mathrm{S}\right.$, $110^{\circ}-120^{\circ} \mathrm{E}$ ). (c) The lead-lag correlation between the two time series. Positive SST anomalies in the Niño-3.4 region indicate an El Niño condition in the Pacific. The dashed lines in (c) denote the $99 \%$ confidence level. 
$20 \mathrm{~W} \mathrm{~m}^{-2}$, respectively (Vialard et al. 2013). The 2018/19 field campaign was proceeded by a weak convective event in the Indonesian-Australian Basin in early-mid-November 2018. The first eastward-propagating MJO (MJO1) arrived in the region around mid-December and reached the Pacific Ocean in late December (Fig. 2). Note that there were no large deep convection

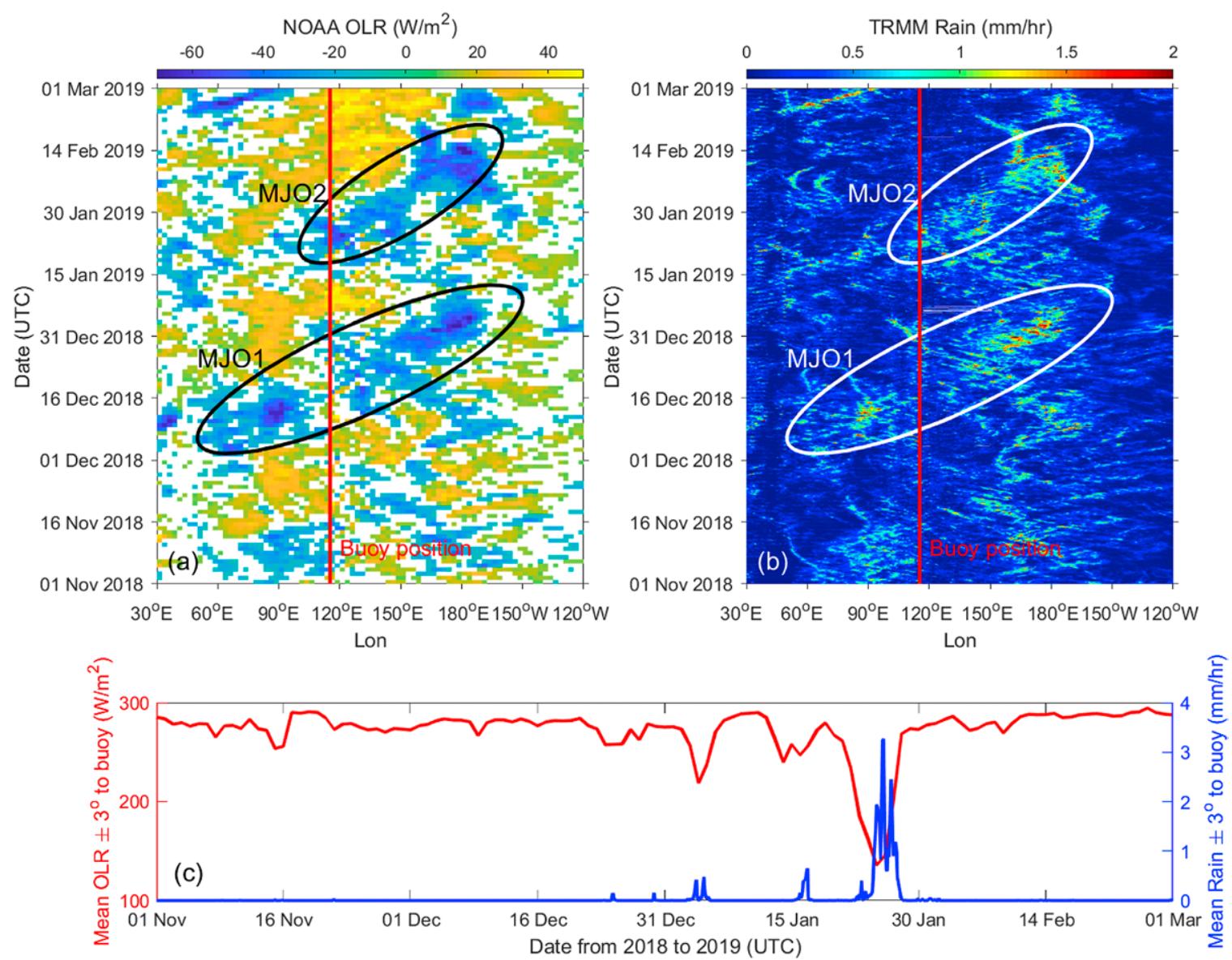

Fig. 2. (a) Daily OLR anomalies and (b) TRMM 3B42RT, version 7, precipitation rates averaged over $20^{\circ} \mathrm{S}-10^{\circ} \mathrm{N}$ in the Indo-Pacific Ocean during November 2018-February 2019. The solid red lines denote the longitude of the Bailong buoy system. The ellipses denote the active phases of the two MJOs. (c) The time series of satellite measurements averaged within $3^{\circ}$ of the buoy position.

features in the longitude range of the Maritime Continent associated with the passage of MJO1. The rainfall in the northern Australia brought by MJO1 was insufficient to reach the monsoon onset threshold (H. Hendon, personal communication). The relationship between the cool SST in the southeast Indian Ocean and the relatively weak MJO convection in December 2018 is uncertain (e.g., Hendon et al. 1999). Using the rainfall record of northern Australia (Marshall and Hendon 2014), the Australian monsoon onset did not occur until late January 2019, upon the arrival of the second eastward-propagating MJO (MJO2). MJO2 interacted with category 2 Tropical Cyclone (TC) Riley (Fig. SB3), which also helped to drive intensified rainfalls in northern Australia. According to the Australian rainfall anomalies north of $25^{\circ} \mathrm{S}$ using a Bureau of Meteorology (BoM) reanalysis (http://poama.bom.gov.au/project/s2s/monsoon/monsoon.html), the active Australian monsoon period started from 30 January 2019 and lasted only for 1 week during the 2018/19 austral summer, one of the driest monsoon periods on record.

The active phases of the MJOs during the field campaign period is defined using the meridionally averaged OLR anomalies at the buoy longitude (Figs. 2 and 3): the active phase of MJO1 spanned from 13 to 20 December 2018 at the mooring location; and that of MJO2 spanned from 19 to 29 January 2019; both started during phase 4 of the MJOs (Wheeler 
and Hendon 2004) (www.bom.gov.au/climate /mjo/), or when the deep convection of the MJOs was located at the Maritime Continent. During the active phase of MJO1, air humidity has large fluctuations between the dry and wet states, and the wet state was fully established toward the end of December 2018 (Fig. 3, Fig. ES2). A low-humidity period during 16-20 December might be influenced by the dry southerly winds from the Australian continent, as shown in the Analysis Chart Archive from the Bureau of Meteorology (www.bom.gov.au/australia /charts/archive/index.shtml). There was a lowsurface-air-pressure signal near the end of December, but it was not associated with any local synoptic weather patterns, according to the Bureau of Meteorology chart. The surface wind measured at the buoy was generally from the west to southwest, except around 17 January 2019 at the onset of MJO2 convection, when easterly wind was observed, and during 25-28 January under the influence of TC Riley (SB3). The active phases of the MJOs were generally associated with low sea level pressure and high wind speed, which were preceded with lowwind periods of less than $5 \mathrm{~m} \mathrm{~s}^{-1}$. After the passage of MJO2, the wind speed weakened until the end of February 2019.

Significant diurnal variations of SST and surface air temperature were observed during the low-wind periods, in the absence of wind stirring, the feature of MJO's suppressed phase (Fig. 3). Both the surface air temperature and SST steadily rose prior to the onset of the MJO1 convection, and then experienced a sharp drop of $\sim 2^{\circ} \mathrm{C}$ during the MJO1 convective phase. The SST rose again at the buoy site after the passage of the MJO1 active phase, with peak SST reaching $30^{\circ} \mathrm{C}$ just before the arrival of the $\mathrm{MJO} 2$ active phase. In other words, the accumulation of heat (and associated moisture) preceded the onset of the MJO active phase. MJO2 and TC Riley then drove a $\sim 3^{\circ} \mathrm{C} \mathrm{SST} \mathrm{drop} \mathrm{at} \mathrm{the} \mathrm{buoy} \mathrm{site.}$

\section{Featured research studies in the experiment}

Strong DV SST events captured by fast profiling floats. A diurnal cycle of SST is observed when the absorption of insolation exceeding the outgoing heat near the ocean surface, in the absence of wind stirring (Fig. SB4). There were two strong DV SST events that occurred in December 2018, starting on 2 and 30 December 2018, respectively, with dSST $>1.5^{\circ} \mathrm{C}$ (Figs. 3-5). Both events were
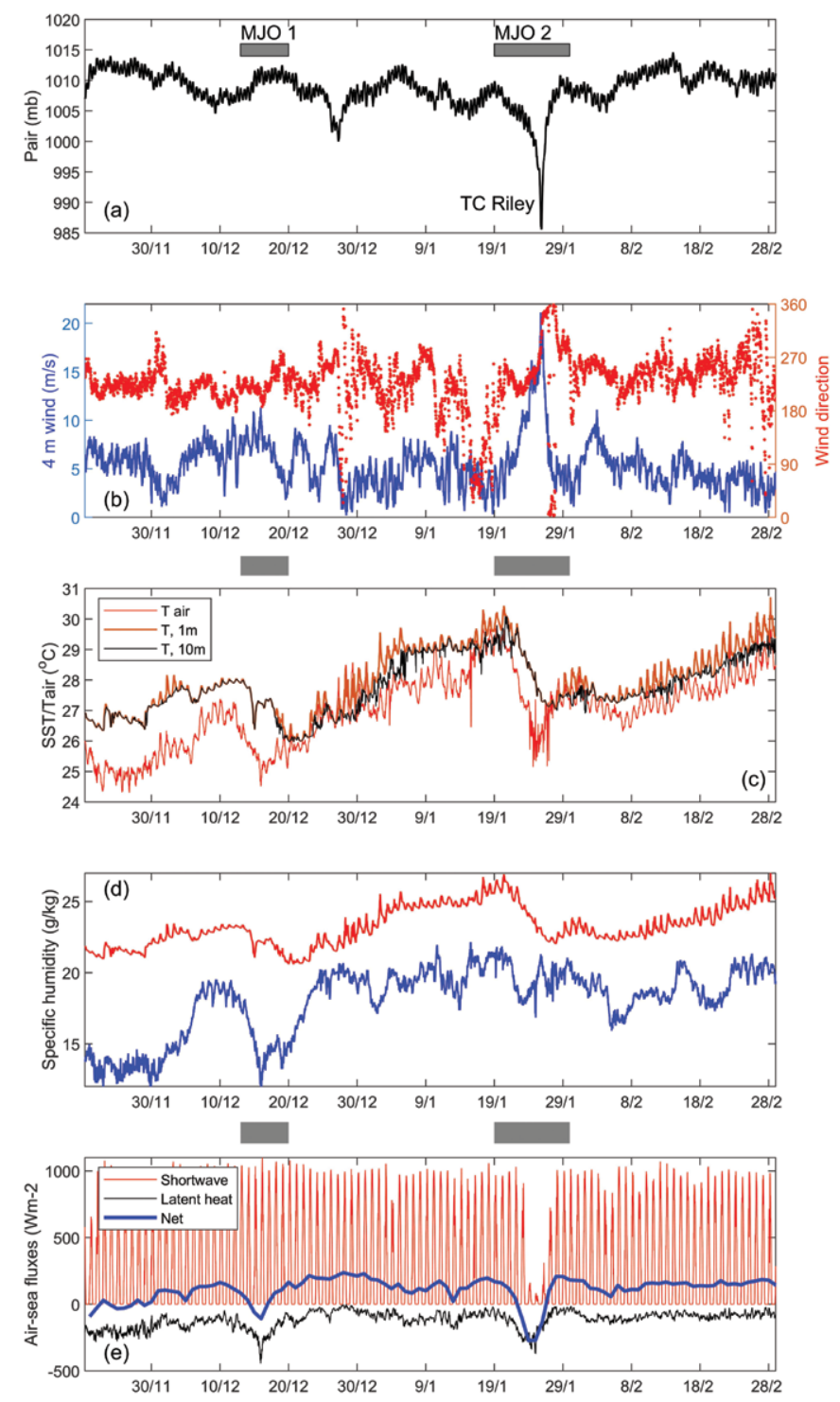

Fig. 3. (a) Sea level pressure, (b) wind speed and direction at 4-m height above the sea surface, (c) air temperature at 3-m height above the sea surface and ocean temperatures at 1- and 10-m depth below the sea surface, (d) specific humidity at 3-m height above the sea surface (blue line) and at sea surface derived from SST (red line), and (e) shortwave radiation, latent heat flux, and net air-sea heat flux, measured on the Bailong buoy. The net heat flux is derived from the Bailong buoy surface data (based on COARE algorithm; Fairall et al. 2003). The sampling frequency is $30 \mathrm{~min}$ and in (e), the net heat flux is averaged daily. The gray bars denote the convective periods of the two MJO events. 


\section{Tropical Cyclone Riley}

The tropical disturbance Riley was identified by BoM in the Indonesian-Australian Basin around 15 January 2019 (www.bom.gov.au/cyclone/history/index.shtml). It became a category 2 tropical cyclone on 26 January 2019 (Fig. SB3). The storm initially moved southward, and then moved westward after 24 January, without making landfall in Australia. On 26 January, the storm passed the Bailong buoy, with a translation speed of $\sim 6 \mathrm{~m} \mathrm{~s}^{-1}$. The closest distance of the storm eye to the buoy was $\sim 60 \mathrm{~km}$, with a maximum wind speed of $\sim 33.4 \mathrm{~m} \mathrm{~s}^{-1}$, and a radius of maximum wind of $\sim 40 \mathrm{~km}$. Satellite imagary clearly shows the rainbands around TC Riley. The precipitation rate within $\pm 3^{\circ}$ of the FIO buoy position is measured to be more than $4 \mathrm{~mm} \mathrm{~h}^{-1}$ at its peak. Tropical cyclones can induce significant wind-driven current, causing strong shear instability and cooling of the upper ocean.
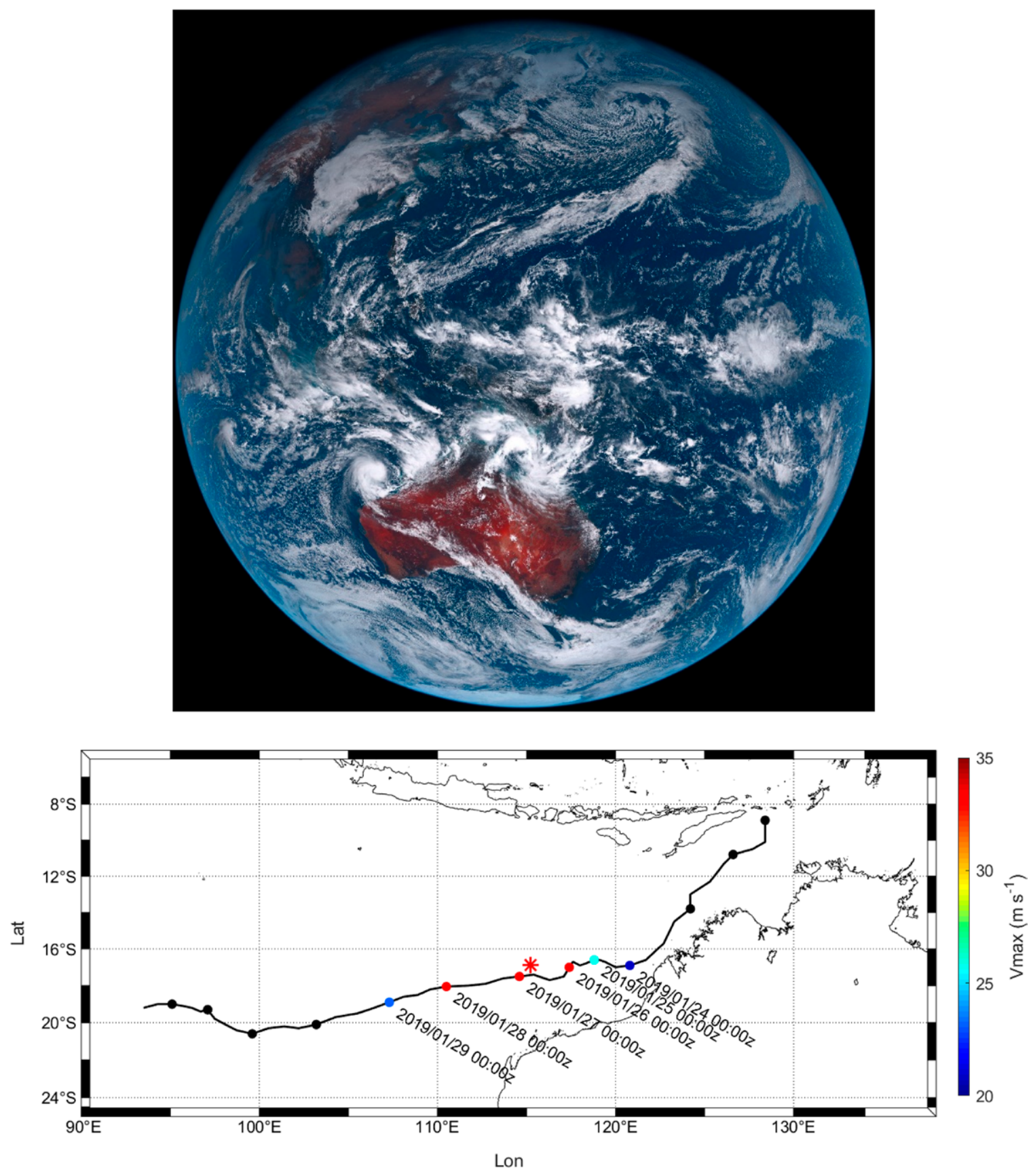

Fig. SB3. (top) Himawari-8 satellite image on 25 Jan 2019, showing Tropical Cyclone Riley off the northwest coast of Australia. (bottom) The trajectory of TC Riley (time interval between dots is 1 day) off northern Australia. The storm passed the buoy (red asterisk) on 26 Jan 2019, with a maximum wind speed $V_{\max }$ (colors) of more than $30 \mathrm{~m} \mathrm{~s}^{-1}$. The satellite image was obtained from the Japan Meteorology Agency website: https://www.data.jma.go.jp/mscweb/data/himawari/index.html. 
associated with low wind speed and low cloud cover (Gentemann et al. 2003; Matthews et al. 2014), during the suppressed phases of the two MJO events. The DV SST was also high during the second half of February 2019, after the passage of MJO2; however, most of the profiling floats had stopped sampling.

On 3 December 2018, the significant DV SST event in the Indonesian-Australian Basin was captured by the Himawari-8 satellite measurements (Fig. 4). DV SST in regions covered by persistent clouds cannot be detected. Nevertheless, substantial spatial variations of DV SST amplitude were observed. The DV SST was high along the Australian coastal regions and extended to the northwest, covering the field work region; low DV SST regions existed to the east. Most of the $d S S T$ near the profiling floats were $>1.5^{\circ} \mathrm{C}$, consistent with the buoy (Fig. 3) and profiling floats (Fig. 5) measurements. Thus, the profiling floats sampled a region with relatively high DV SST in the Indonesian-Australian Basin on 3 December 2018.

\section{Diurnal variation of SST and upper-ocean temperature}

Before sunrise, net outgoing longwave radiation, latent heat flux, and sensible heat flux cool the near sea surface waters, and thereby the nighttime convective mixing exists above the seasonal thermocline (Fig. SB4). After sunrise, the absorption of insolation increases the SST to a peak (SST max $_{\text {ax }}$ in the afternoon. The penetrating solar radiation also increases temperature gradient near the surface and forms a diurnal warm layer (DWL). The DWL with a high gradient of potential density can stabilize the upper ocean and inhibit the turbulent mixing (Fairall et al. 2003; Brainerd and Gregg 1993). The nighttime convective mixing will repeat and erode the DWL after the sunset. The magnitude of DV SST is evaluated by computing the difference between daily maximum SST, SST max and the foundation SST, SST $_{\text {fnd }}$ which is defined using the mean SST before the sunrise (e.g., Bernie et al. 2005; Zhang et al. 2016). The window of averaging between 0000 and

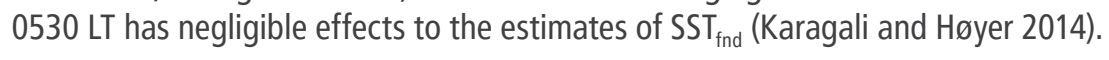

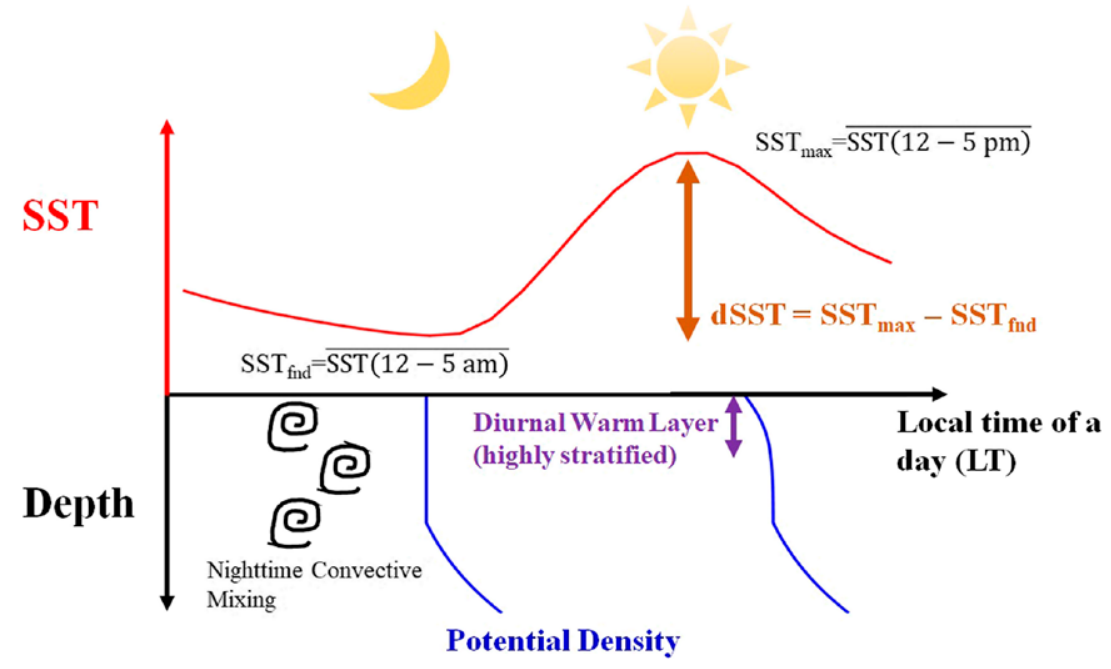

Fig. SB4. Schematic plot of DV SST (red line) and potential density profiles in the upper ocean (blue lines). During a diurnal cycle, peak SST $\left(\mathrm{SST}_{\max }=\right.$ mean SST from 1200 to $1700 \mathrm{LT}$ ) typically occurs in the local afternoon. The magnitude of DV SST is quantified by computing the dSST, the difference between the daytime peak and nighttime foundation SST (SST fnd $_{\text {) }}$ during a diurnal cycle. In this study, we have used the mean SST from 1200 to 1700 LT as SST max $_{\text {, }}$ and from 0000 to $0500 \mathrm{LT}$ as $\mathrm{SST}_{\text {fnd }}$.

The profiling float data not only accurately captured the DV SST variability, but also revealed the evolution of ocean mixed layer, which is critical for the DV SST development. (The base of the surface mixed layer is defined as the depth where difference between potential density $\rho$ and the mean $\rho$ in the upper $3 \mathrm{~m}$ is equal to or greater than $0.1 \mathrm{~kg} \mathrm{~m}^{-3}$.) The mixed layer depth was about $50 \mathrm{~m}$ before the onset of the strong DV SST event in early December 2018 (Fig. 5). Shallowing of the mixed layer and strong DV SST developed within 2 days from 2 December 2018. The DV SST magnitude was more than $2^{\circ} \mathrm{C}$, with peak SST reaching $29^{\circ} \mathrm{C}$, from a background mixed layer temperature of just above $26^{\circ} \mathrm{C}$ (Fig. 4). After the first strong DV SST event, three more ALAMO floats failed before 21 December 2018, so that the second strong DV SST event of more than $2^{\circ} \mathrm{C}$ was only captured by a single ALAMO float, 9207 (Fig. 5).

Buoyancy frequency $N^{2}$, which is proportional to the vertical gradient of potential density, was 
calculated to explore the density stratification during the strong DV SST events (Fig. 5). High $N^{2}$ can inhibit the turbulent mixing. After sunrise, the heating from solar insolation started to form diurnal stratification (diurnal warm layer) near the ocean surface. The thermal stratification

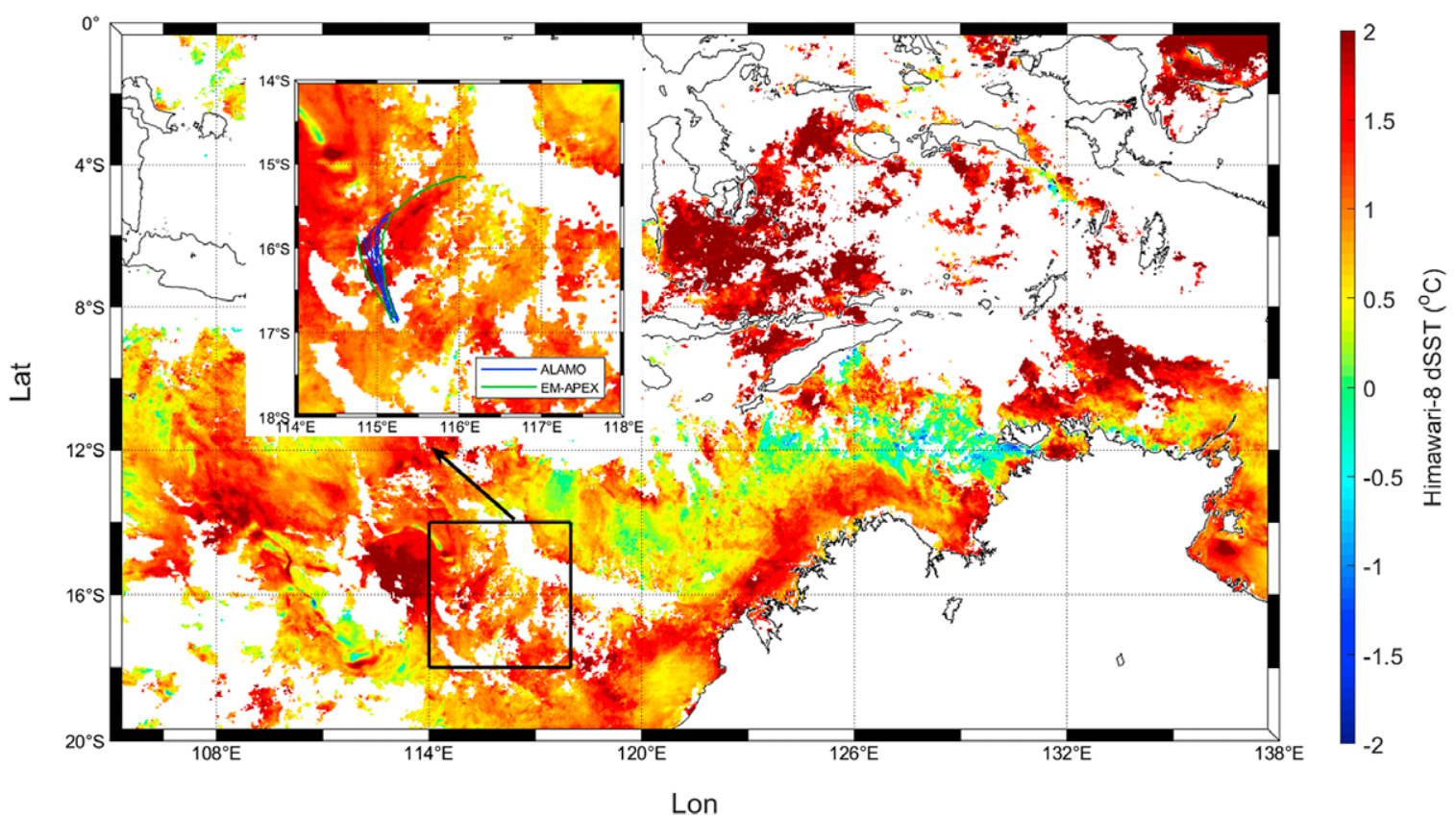

Fig. 4. Trajectories of six ALAMO floats (blue lines in the inset) and two EM-APEX floats (green lines in the inset) from 22 Nov to 3 Dec 2018. The background map shows dSST on 3 Dec, estimated using the Himawari-8 satellite observations. SST in regions covered by clouds cannot be detected by the infrared measurement.
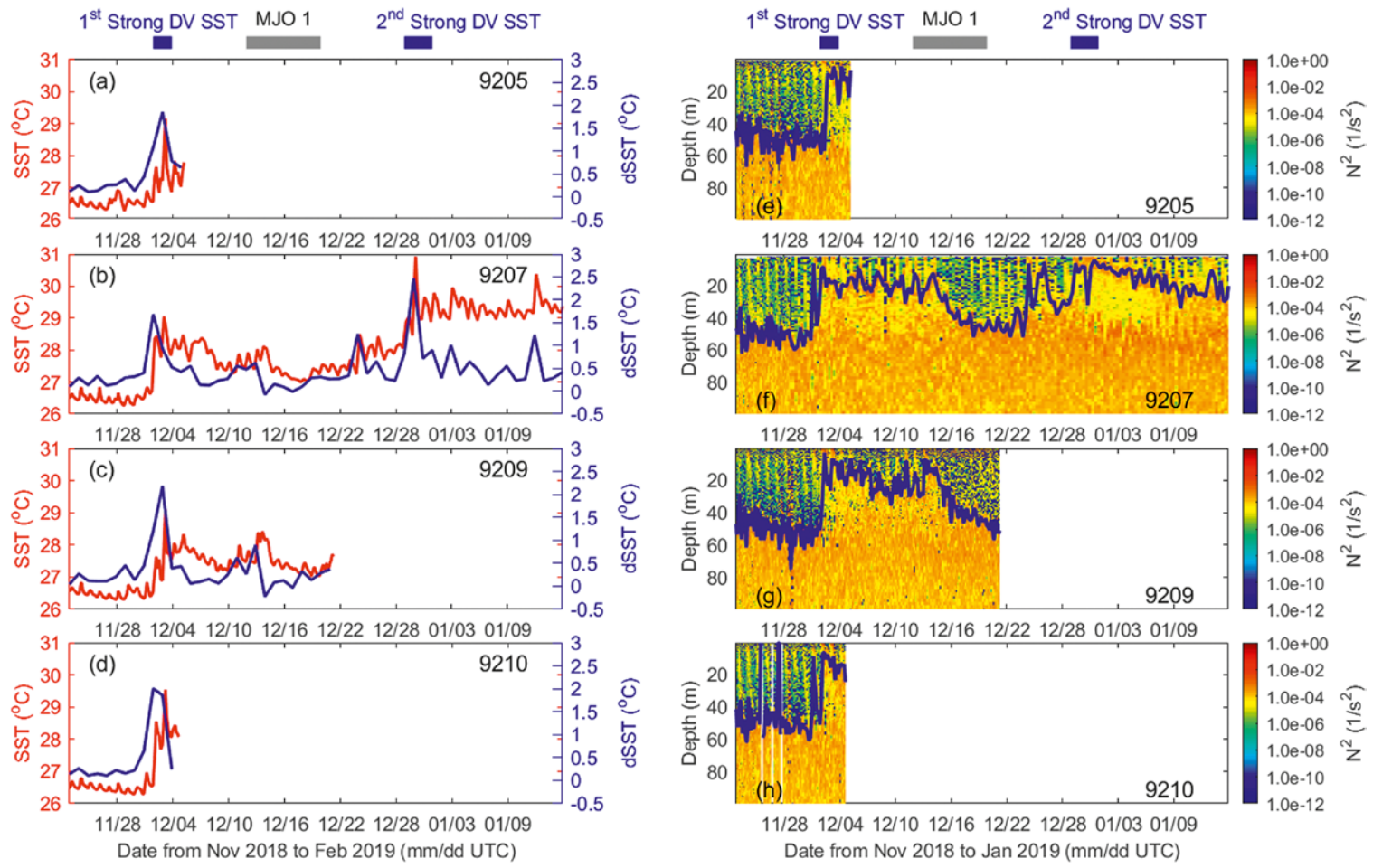

Fig. 5. (a)-(d) SST (red lines) and estimates of dSST (blue lines) and (e)-(h) surface mixed layer depth (blue lines) and buoyancy stratification $N^{2}$ (shading) derived from four ALAMO float measurements [(top to bottom) 9205, 9207, 9209, and 9210, respectively]. The negative values of $N^{2}$ are denoted with the black dots. Two strong DV SST events (on 2 and $30 \mathrm{Dec}$ ) are identified as $d S S T>1.5^{\circ} \mathrm{C}$. 
prevented the mixing of ocean surface warm water with colder water in the subsurface layer, so that the shallow warm layer was insulated from the thermocline water below to provide a positive feedback to eventuate the strong DV SST event. The high vertical sampling resolution of the ALAMO floats was able to depict the fine warm-layer structure in the top meter of the upper ocean. The surface mixed layer shoaled by more than $40 \mathrm{~m}$ within 2 days during the two strong DV SST events, starting from 1 and 29 December 2018, respectively. Compared to the SST before the strong DV SST events, the daily mean SST at most floats increased by at least $1^{\circ} \mathrm{C}$, and the higher SST was sustained for more than a week, presumably contributed by the increasing stratification in the upper ocean, prohibiting vertical turbulent mixing. Understanding the dynamics of the warm layer is critical for simulating the DV SST in numerical forecasting models.

Upper-ocean responses to the MJOs and the tropical cyclone. During December 2018February 2019, there was net heat input into the ocean via the air-sea interface on most days except during the two short periods of the active MJOs, in mid-December 2018 and again in late January 2019 (Fig. 3). The average net heat flux into the ocean during December 2018February 2019 was $121 \mathrm{~W} \mathrm{~m}^{-2}$, which would warm a 50-m surface mixed layer by more than $4^{\circ} \mathrm{C}$ during a 3-month period. Based on the buoy observations, the surface temperature rose by less than $2^{\circ} \mathrm{C}$. Thus, the heat input might be partly balanced by a northward wind-driven transport of cooler waters from the south, due to the prevailing westerly winds. The net heat flux into the ocean during the 2018/19 austral summer was somewhat higher than the climatology derived from OAFlux, a daily air-sea heat flux product (Fig. ES1; Yu et al. 2008), which might be associated with the cooler SST that enhanced ocean heat uptake.

The two active phases of the MJOs were associated with large latent heat releases from the ocean (Fig. 3). MJO1 induced a peak net heat loss of over $100 \mathrm{~W} \mathrm{~m}^{-2}$ on 16 December 2018. MJO2, in conjunction with the tropical cyclone, caused a heat loss over a 4-day period, with peak heat loss over $270 \mathrm{~W} \mathrm{~m}^{-2}$ for 2 days on $24-25$ January 2019. There was $\sim 2^{\circ} \mathrm{C}$ drop in SST in MJO1 and a $3^{\circ} \mathrm{C}$ drop in $\mathrm{MJO} 2$ in response to the surface heat losses (Fig. 3). A $1.5^{\circ} \mathrm{C}$ drop of SST was observed under the influence of a strong MJO event in conjunction with a tropical cyclone during a field campaign in the western Indian Ocean in early 2008 (Vialard et al. 2008, 2009). Thus, the SSTs in the eastern Indian Ocean warm pool appear to be more susceptible to MJO disturbances, which is supported by the $(\sim 50 \%)$ higher ratio between intraseasonal SST and OLR variability in the Indonesian-Australian Basin, especially the southern half of the basin, compared with the western Indian Ocean (Fig. ES3; SST data are based on a high-resolution multisensor SST analysis; Beggs et al. 2011). Upper-ocean temperatures rose again after MJO2 toward the end of February 2019, which was captured by both the buoy and one ALAMO float. Prior to or during the active phase of the MJOs, precipitation and horizontal advection anomalies may freshen the ocean surface layer (Fig. 6). The fresher water may then be subducted underneath the relatively
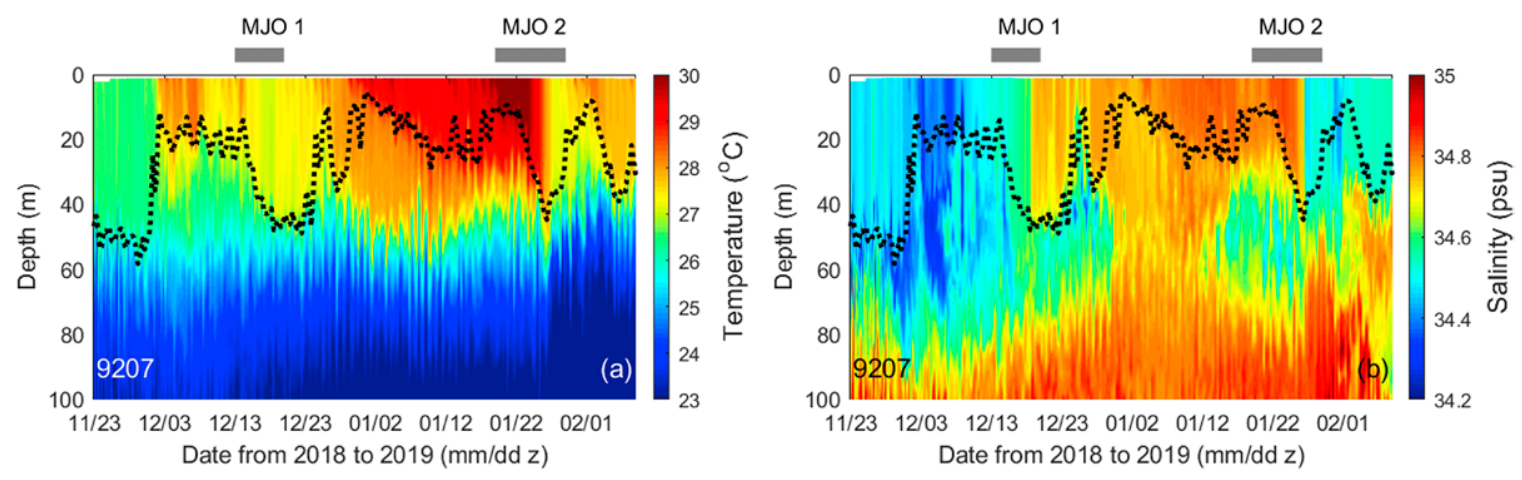

Fig. 6. Measured (a) temperature and (b) salinity from ALAMO float 9207. The black dashed lines denote the surface mixed layer depth. 
high-salinity water at $\sim 60$-m depth after the passage of the MJO convection.

The passage of the MJO convections brought strong westerly winds to force eastward surface currents, which interacted with the rich mesoscale eddy field in the Indonesian-Australian Basin (Figs. 7 and 8). A cyclonic eddy persisted to the northeast of the deployment site in late November-early December 2018, inducing a predominant northward drift of the profiling floats (Fig. 7). The eddy weakened and shifted slightly to the west from early December. In the meantime, a high sea level anomaly center approached the area from the east, north of $15^{\circ} \mathrm{S}$, inducing southeastward surface geostrophic current anomalies. In late December 2018, the
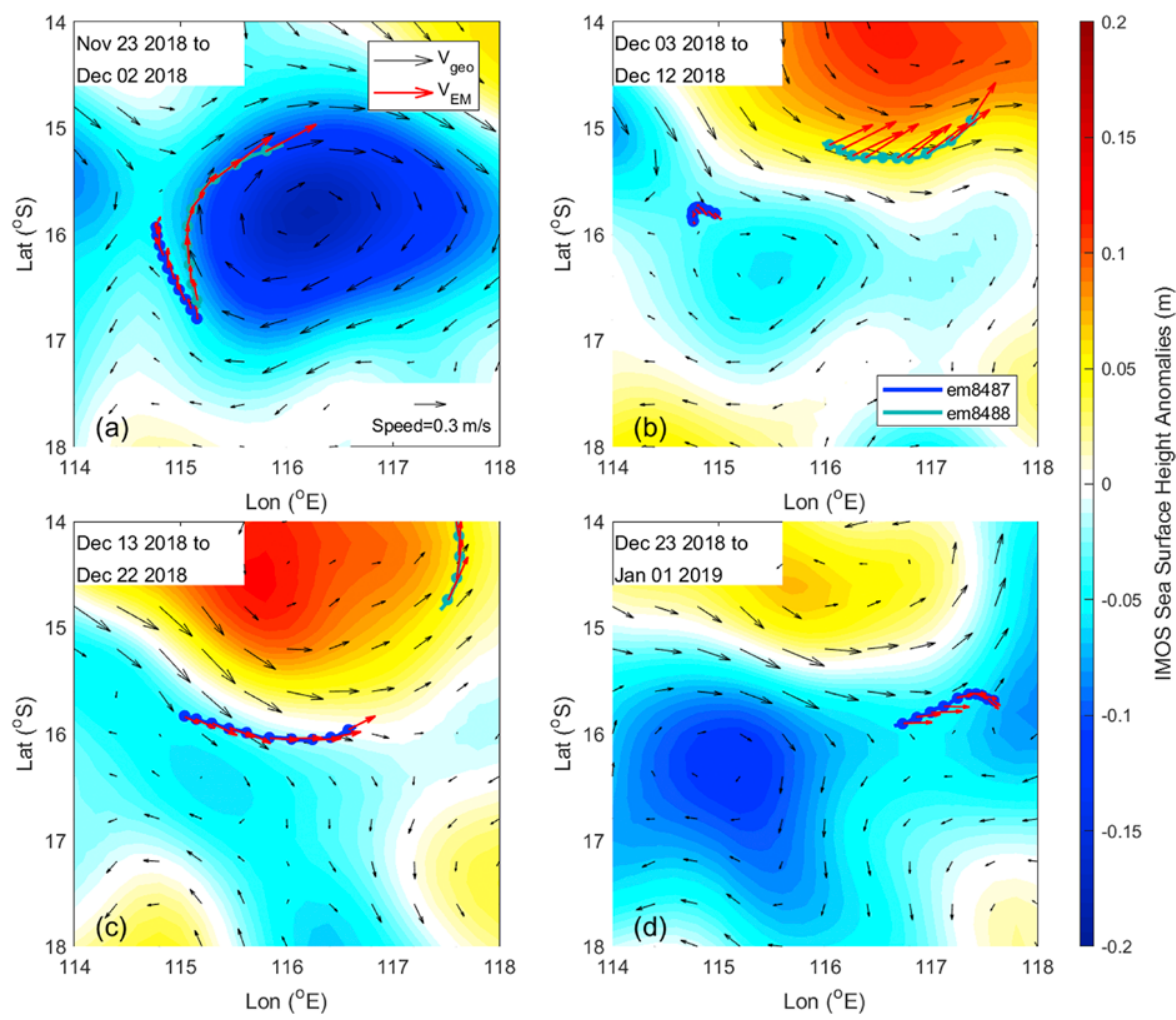

Fig. 7. Trajectories of the two EM-APEX floats (interval between dots = 1 day), em8487 (blue line), and em8488 (cyan line) on maps of 10-day-averaged sea surface height anomalies (shading) and geostrophic current anomalies (black arrows) derived from satellite altimeter data (obtained from IMOS) during November-December 2018. The red arrows are measured current velocity from the EM-APEX floats averaged in the upper 50-m depth.

cyclonic eddy seemed to reemerge, centered around $115^{\circ} \mathrm{E}$. During the active phase of MJO1 from 13 to 20 December 2018, the EM-APEX float em8487 was located at the south of one anticyclonic eddy (Fig. 7). Colder water below the surface mixed layer was entrained into the surface layer during the MJO convective phase, likely due to the enhanced mixing induced by shear instability (Fig. 6), as the surface mixed layer was deepened from 10 to $50 \mathrm{~m}$.

This basic description of the oceanographic conditions during the field campaign will provide background information for future ocean mixing and air-sea coupling studies utilizing the dataset.

Inertial motions and internal tides. Vertical turbulence mixing plays a crucial role in the SST evolution. Ocean processes affecting the turbulence mixing include ocean stratification, internal waves (oscillations of thermocline depth at tidal or other frequencies), inertial waves (interior fluid motions using Earth rotation as restoring force, typically driven by surface winds), and background current shears. Both internal waves and inertial waves can propagate from their generation sites and cause enhanced turbulence mixing when they break. The roles of different processes in the SST budget on the MJO time scale have been assessed in other Indian Ocean regions (e.g., Cuypers et al. 2013); however, mixed layer processes have not been well observed in the Indonesian-Australian Basin, where the strong internal tidal energy may be an important contributing factor to the vertical mixing. Strong internal (tide) wave influence and water mass interleaving features were also observed in the float data (Fig. 6).

During the CSHOR-FIO field program, the two EM-APEX floats, em8487 and em8488, were deployed on 22 November 2018, and continuously obtained temperature, salinity, and current 
velocity profiles in the upper $300 \mathrm{~m}$ for 1.5 months (Fig. 7), providing a rich dataset to study the interplay among MJO forcing, mesoscale eddy, inertial waves, and internal waves in affecting the surface mixed layer processes in the Indonesian Australian Basin. The strong cold-core cyclonic eddy located to the east of the floats' initial positions drove the floats northward in the first 10 days. Being entrained into the cyclonic eddy, the drifting speed of float em8488 was much faster than em8487. After the cyclonic eddy dissipated in about 10 days, the floats were then affected by the positive sea level anomalies associated with the warm-core anticyclonic eddy in the north and started to drift eastward. The float motion in general agreed with the geostrophic current due to the low wind speed (i.e., weak wind-driven Ekman current) during most parts of the field experiment (Fig. 3). Most measured current velocity from em8487 was less than $0.3 \mathrm{~m} \mathrm{~s}^{-1}$ in the upper $50 \mathrm{~m}$ (red arrows in Figs. 7 and 8), except before and during
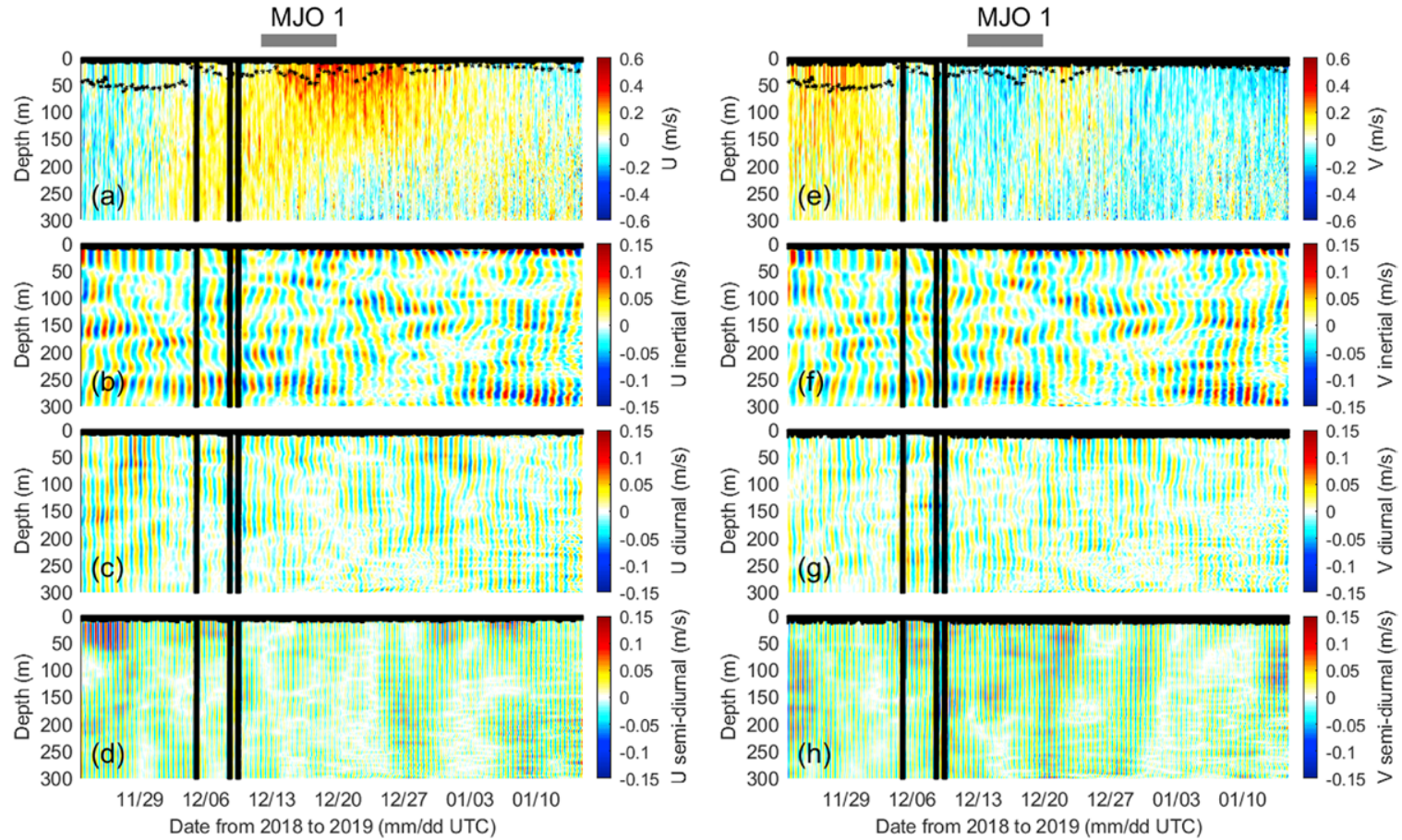

Fig. 8. (a),(e) Measurements of current velocity taken by float em8487. The measured current velocity is decomposed with harmonic analysis within a successive window of \pm 2 days, assuming the current is constituted by (b),(f) one inertial wave, (c),(g) one diurnal tide, and (d),(h) one semidiurnal tide. Columns show the (left) zonal and (right) meridional components. The black dashed lines and dots denote the mixed layer depth and missing measurements, respectively.

the active convection phase of MJO1, when the measured surface velocity steered to the north compared with the satellite-estimated geostrophic current (Fig. 7b).

The current velocity measurement from em8487 in successive \pm 2 -day windows are used in a harmonic analysis (Fig. 8), which assumes the ocean current constituted by one inertial wave (period $\approx 43.5 \mathrm{~h}$ ), one diurnal $\mathrm{K}_{1}$ tide (period $=24 \mathrm{~h}$ ) and one semidiurnal $\mathrm{M}_{2}$ tide (period $=12.42 \mathrm{~h}$ ). The diurnal $\left(\mathrm{K}_{1}\right)$ and semidiurnal (M2) tidal motion results from the gravity of the moon. The magnitude of inertial motions was generally less than $0.15 \mathrm{~m} \mathrm{~s}^{-1}$. Besides the inertial waves in the upper $50 \mathrm{~m}$ generated by the local wind, internal waves below $100-\mathrm{m}$ depth (i.e., below the seasonal thermocline) may be due to vertical propagations of internal waves cascaded from inertial waves generated from other locations.

The semidiurnal tides are significant, up to $0.15 \mathrm{~m} \mathrm{~s}^{-1}$. The magnitude of semidiurnal tides was generally higher than the diurnal tides. The observation of stronger semidiurnal tides in the region was consistent with the previous observation and model results (Holloway et al. 2001; Rayson et al. 2011). Similar with the internal waves at the inertial frequency, the 
EM-APEX float measurements of semidiurnal internal tides may be used for exploring the tidal energy flux (e.g., Lien et al. 2013) around the Maritime Continent. It will also be interesting to study the breaking of internal waves, which would enhance the vertical mixing in the upper ocean (e.g., Cuypers et al. 2017). Vertical mixing due to wind-generated internal gravity waves could drive an upper-ocean heating rate up to $0.42^{\circ} \mathrm{C} \mathrm{month}{ }^{-1}$, as observed in the western Indian Ocean (Cuypers et al. 2013).

\section{Summary}

The CSHOR-FIO atmosphere-ocean field campaign in the Indonesian-Australian Basin during the austral summer of 2018/19 collected rich surface meteorology and ocean profiling data from diurnal to intraseasonal time scales, to study the interplay among the MJO forcing, mesoscale eddy, inertial waves, and internal waves in affecting the surface mixed layer processes in the Indonesian-Australian Basin. The dataset will provide validations of high-resolution numerical models to study the coupled processes associated with the evolution of the MJO in the region. The success of the field campaign was built on a bilateral collaboration between CSHOR and FIO. Whereas the surface meteorology buoy provided realtime measurements of key air-sea exchange processes associated with the MJOs, tropical cyclones, and the transition between the Australian monsoon and the trade wind regimes, the influences from two MJO events and one tropical cyclone on the upper ocean were captured during the core period of the campaign (December 2018-February 2019) by most of the autonomous profiling instruments. The campaign was a unique combination of traditional buoy measurement and the new cost-effective profiling technology to a process study. The buoy system lasted well beyond the full transition from premonsoon onset through the end of the monsoon of 2018/19 austral summer. The data will be crucial to evaluate reanalysis products for the Indonesian-Australian Basin where large uncertainties of air-sea net heat flux exist (e.g., Yu et al. 2007).

The field campaign provides unique observations of simultaneous air-sea exchanges and upper-ocean variability in the Indonesian-Australian Basin for the first time, building upon the process studies in the Indo-Pacific warm pool started from the Coupled Ocean-Atmosphere Research Program (COARE) back in 1992/93 (Webster and Lukas 1992). It appears that SSTs in the region may be more susceptible to the MJO associated atmospheric forcing. The data can be used to explore multiscale processes from diurnal to MJO variability, from warm layer-mixed layer processes to their interactions with strong internal tide activities in the region. The collected data will be used to validate weather and climate forecast models, because previous studies often overlook the air-sea coupling processes in the Indonesian-Australian Basin, which has stronger MJO response compared to other tropical regions. The measurements can also improve our understanding on the oceanographic conditions for the relatively weak MJO variability, and the delayed onset of the Australian summer monsoon rainfall in the tropical north region during the 2018/19 austral summer. The cool SST anomalies may stabilize the atmosphere and inhibit convection in the Indonesian-Australian Basin. The profiling data from ALAMO and EM-APEX floats, which are the main vehicle for the upper-ocean measurements, provide new tools for exploring mixed layer dynamics. This may pave the way of using cost-effective autonomous technology in process studies in other parts of the World Ocean.

$\mathrm{R} / \mathrm{V}$ Investigator revisited the air-sea coupling processes in the eastern part of the Indonesian-Australian Basin during the 2019/20 austral summer, cocontributed from the CSHOR project, with additional atmospheric sounding measurements and more ocean profiling including direct turbulence measurements. The combination of these measurements would allow us to improve the understanding of the coupled ocean-atmosphere processes in the Indonesian Australian Basin. 
Acknowledgments. MF, SW, and JH are supported by the Centre for Southern Hemisphere Oceans Research (CSHOR), which is a joint initiative between the Qingdao National Laboratory for Marine Science and Technology (QNLM), CSIRO, University of New South Wales, and University of Tasmania. Y. Duan is supported by National Natural Science Foundation of China (41706032) and Basic Scientific Fund for National Public Research Institutes of China (2019Q03). We would thank Ryan Crossing for his role as voyage manager to carry out the field works, and to Dirk Slawinski for near-real-time data processing of the profiling float data. Supports from Rebecca Cowley and Craig Hanstein from CSIRO in preparing the float deployments are also appreciated. We thank three anonymous reviewers for critical comments, and we would also thank for the endorsement from the Year of Maritime Continent (YMC) community. The observation data will be released for public use upon the conclusion of the current CSHOR project.

\section{References}

Beal, L. M., and Coauthors, 2019: Executive summary. Ind00S-2: A roadmap to sustained observations of the Indian Ocean for 2020-2030. CLIVAR/G00S Rep. CLIVAR-4/2019/GO0S-237, 9 pp., https://doi.org/10.36071/clivar.rp.4 -1.2019 .

Beggs, H., A. Zhong, G. Warren, O. Alves, G. Brassington, and T. Pugh, 2011: RAMSSA—An operational, high-resolution, regional Australian multi-sensor sea surface temperature analysis over the Australian region. Aust. Meteor. Oceanogr. J., 61, 1-22, https://doi.org/10.22499/2.6101.001.

Bernie, D. J., S. J. Woolnough, J. M. Slingo, and E. Guilyardi, 2005: Modeling diurnal and intraseasonal variability of the ocean mixed layer. J. Climate, 18, 11901202, https://doi.org/10.1175/JCLI3319.1.

Brainerd, K. E., and M. C. Gregg, 1993: Diurnal restratification and turbulence in the oceanic surface mixed layer: 1. Observations. J. Geophys. Res., 98, $22645-$ 22 656, https://doi.org/10.1029/93JC02297.

Cole, R., J. Kinder, C. L. Ning, W. Yu, and Y. Chao, 2011: "Bai-Long": A TAO-hybrid on RAMA. OCEANS'11 MTS/IEEE KONA, Waikoloa, HI, IEEE, https://doi.org /10.23919/OCEANS.2011.6106952.

CSHOR, 2018: Centre for Southern Hemisphere Oceans Research Science Plan 2017 to 2022. CSHOR Rep., 52 pp., https://cshor.csiro.au/wp-content/uploads 12020/06/CSHOR-Science-Plan-August-2018.pdf.

Cuypers, Y., X. Le Vaillant, P. Bouruet-Aubertot, J. Vialard, and M. J. McPhaden, 2013: Tropical storm-induced near-inertial internal waves during the Cirene experiment: Energy fluxes and impact on vertical mixing. J. Geophys. Res. Oceans, 118, 358-380, https://doi.org/10.1029/2012JC007881.

— - P. Bouruet-Aubertot, J. Vialard, and M. J. McPhaden, 2017: Focusing of internal tides by near-inertial waves. Geophys. Res. Lett., 44, 2398-2406, https://doi.org/10.1002/2017GL072625.

DeMott, C. A., N. P. Klingaman, and S. J. Woolnough, 2015: Atmosphere-ocean coupled processes in the Madden-Julian oscillation. Rev. Geophys., 53, 1099-1154, https://doi.org/10.1002/2014RG000478.

Duan, Y., H. Liu, W. Yu, L. Liu, G. Yang, and B. Liu, 2019: The onset of the Indonesian-Australian summer monsoon triggered by the first-branch eastward-propagating Madden-Julian oscillation. J. Climate, 32, 5453-5470, https://doi.org/10.1175/JCLI-D-18-0513.1.

Duvel, J. P., and J. Vialard, 2007: Indo-Pacific sea surface temperature perturbations associated with intraseasonal oscillations of tropical convection. J. Climate, 20, 3056-3082, https://doi.org/10.1175/JCLI4144.1.

Fairall, C. W., E. F. Bradley, J. E. Hare, A. A. Grachev, and J. B. Edson, 2003: Bulk parameterization of air-sea fluxes: Updates and verification for the COARE algorithm. J. Climate, 16, 571-591, https://doi.org/10.1175/1520-0442(2003) 016<0571:BPOASF $>2.0 . C 0 ; 2$.

Gentemann, C. L., C. J. Donlon, A. Stuart-Menteth, and F. J. Wentz, 2003: Diurnal signals in satellite sea surface temperature measurements. Geophys. Res. Lett., 30, 1140, https://doi.org/10.1029/2002GL016291. 
Hashiguchi, H., S. Fukao, M. D. Yamanaka, T. Tsuda, S. W. B. Harijono, and H. Wiryosumarto, 1995: Boundary layer radar observations of the passage of the convection center over Serpong, Indonesia $\left(6^{\circ} \mathrm{S}, 107^{\circ} \mathrm{E}\right)$ during the TOGA COARE intensive observation period. J. Meteor. Soc. Japan, 73, 535-548, https://doi.org/10.2151/jmsj1965.73.2B_535.

Hendon, H. H., C. Zhang, and J. D. Glick, 1999: Interannual variation of the Madden-Julian oscillation during austral summer. J. Climate, 12, 2538-2550, https://doi.org/10.1175/1520-0442(1999)012<2538:IVOTMJ>2.0.C0;2.

Hermes, J. C., and Coauthors, 2019: A sustained ocean observing system in the Indian Ocean for climate related scientific knowledge and societal need. Front. Mar. Sci., 6, 355, https://doi.org/10.3389/fmars.2019.00355.

Holloway, P. E., P. G. Chatwin, and P. Craig, 2001: Internal tide observations from the Australian North West shelf in summer 1995. J. Phys. Oceanogr., 31, 1182-1199, https://doi.org/10.1175/1520-0485(2001)031<1182:ITOFTA >2 $.0 . \mathrm{CO} ; 2$.

Hsu, J.-Y., R.-C. Lien, E. A. D'Asaro, and T. B. Sanford, 2017: Estimates of surface wind stress and drag coefficients in Typhoon Megi. J. Phys. Oceanogr., 47, 545-565, https://doi.org/10.1175/JPO-D-16-0069.1.

Huffman, G. J., and D. T. Bolvin, 2018: Real-time TRMM Multi-Satellite Precipitation Analysis data set documentation. NASA Goddard Space Flight Center Rep., 51 pp., https://pmm.nasa.gov/sites/default/files/document_files/3B4XRT_doc _V7_180426.pdf.

Jayne, S., and N. Bogue, 2017: Air-deployable profiling floats. Oceanography, 30, 29-31, https://doi.org/10.5670/oceanog.2017.214.

Kajikawa, Y., B. Wang, and J. Yang, 2010: A multi-time scale Australian monsoon index. Int. J. Climatol., 30, 1114-1120, https://doi.org/10.1002/joc.1955.

Karagali, I., and J. L. Høyer, 2014: Characterisation and quantification of regional diurnal SST cycles from SEVIRI. Ocean Sci., 10, 745-758, https://doi .org/10.5194/os-10-745-2014.

Kim, H. M., P. J. Webster, V. E. Toma, and D. Kim, 2014: Predictability and prediction skill of the MJO in two operational forecasting systems. J. Climate, 27, 5364-5378, https://doi.org/10.1175/JCLI-D-13-00480.1.

Lee, J. Y., B. Wang, M. C. Wheeler, X. Fu, D. E. Waliser, and I. S. Kang, 2013: Realtime multivariate indices for the boreal summer intraseasonal oscillation over the Asian summer monsoon region. Climate Dyn., 40, 493-509, https://doi .org/10.1007/s00382-012-1544-4.

Lien, R.-C., T. B. Sanford, S. Jan, M.-H. Chang, and B. B. Ma, 2013: Internal tides on the East China Sea continental slope. J. Mar. Res., 71, 151-185, https://doi .org/10.1357/002224013807343461.

Marshall, A. G., and H. H. Hendon, 2014: Impacts of the MJO in the Indian Ocean and on the western Australian coast. Climate Dyn., 42, 579-595, https://doi .org/10.1007/s00382-012-1643-2.

Matthews, A. J., D. B. Baranowski, K. J. Heywood, P. J. Flatau, and S. Schmidtko, 2014: The surface diurnal warm layer in the Indian Ocean during CINDYIDYNAMO. J. Climate, 27, 9101-9122, https://doi.org/10.1175/JCLI-D-14-00222.1.

McPhaden, M. J., and Coauthors, 2009: RAMA: The research moored array for African-Asian-Australian monsoon analysis and prediction. Bull. Amer. Meteor. Soc., 90, 459-480, https://doi.org/10.1175/2008BAMS2608.1.

Moum, J. N., and Coauthors, 2014: Air-sea interactions from westerly wind bursts during the November $2011 \mathrm{MJO}$ in the Indian Ocean. Bull. Amer. Meteor. Soc. 95, 1185-1199, https://doi.org/10.1175/BAMS-D-12-00225.1.

Rayson, M. D., G. N. Ivey, N. L. Jones, M. J. Meuleners, and G. W. Wake, 2011: Internal tide dynamics in a topographically complex region: Browse Basin, Australian North West shelf. J. Geophys. Res., 116, C01016, https://doi. org/10.1029/2009JC005881.

Sanford, T. B., J. H. Dunlap, J.A. Carlson, D. C. Webb, and J. B. Girton, 2005:Autonomous velocity and density profiler: EM-APEX. Proc. Eighth Working Conf. on Current Measurement Technology, Southampton, United Kingdom, IEEE/OES, 152-156.

_ J. F. Price, and J. B. Girton, 2011: Upper-ocean response to Hurricane Frances (2004) observed by profiling EM-APEX floats. J. Phys. Oceanogr., 41, 1041-1056, https://doi.org/10.1175/2010JP04313.1.
Seo, H., A. C. Subramanian, A. J. Miller, and N. R. Cavanaugh, 2014: Coupled impacts of the diurnal cycle of sea surface temperature on the Madden-Julian oscillation. J. Climate, 27, 8422-8443, https://doi.org/10.1175/JCLI-D-14-00141.1.

Vialard, J., G. Foltz, M. McPhaden, J.-P. Duvel, and C. de Boyer Montegut, 2008: Strong Indian Ocean sea surface temperature signals associated with the Madden-Julian oscillation in late 2007 and early 2008. Geophys. Res. Lett., 35, L19608, https://doi.org/10.1029/2008GL035238.

Chagos thermocline ridge region. Bull. Amer. Meteor. Soc., 90, 45-62, https:// doi.org/10.1175/2008BAMS2499.1.

— , K. Drushka, H. Bellenger, M. Lengaigne, S. Pous, and J. P. Duvel, 2013: Understanding Madden-Julian-induced sea surface temperature variations in the north western Australian Basin. Climate Dyn., 41, 3203-3218, https://doi .org/10.1007/s00382-012-1541-7.

Wang, B., and X. Xie, 1997: A model for the boreal summer intraseasonal oscillation. J.Atmos. Sci., 54, 72-86, https://doi.org/10.1175/1520-0469(1997) 054<0072:AMFTBS>2.0.C0;2.

Wang, X. H., and H. Zhang, 2017: Effects of Australian summer monsoon on sea surface temperature diurnal variation over the Australian northwestern shelf. Geophys. Res. Lett., 44, 9856-9864, https://doi.org/10.1002 12017GL075008.

Webster, P. J., and R. Lukas, 1992: TOGA COARE: The Coupled Ocean-Atmosphere Response Experiment. Bull. Amer. Meteor. Soc., 73, 1377-1416, https://doi .org/10.1175/1520-0477(1992)073<1377:TCTCOR>2.0.C0;2.

Wheeler, M. C., and H. H. Hendon, 2004: An all-season real-time multivariate MJO index: Development of an index for monitoring and prediction. Mon. Wea. Rev., 132, 1917-1932, https://doi.org/10.1175/1520-0493(2004)132<1917: AARMMI>2.0.CO;2.

Wijesekera, H. W., and Coauthors, 2016: ASIRI: An ocean-atmosphere initiative for Bay of Bengal. Bull. Amer. Meteor. Soc., 97, 1859-1884, https://doi .org/10.1175/BAMS-D-14-00197.1.

Yoneyama, K., and Coauthors, 2008: MISMO field experiment in the equatorial Indian Ocean. Bull. Amer. Meteor. Soc., 89, 1889-1904, https://doi.org /10.1175/2008BAMS2519.1.

_ C. Zhang, and C. N. Long, 2013: Tracking pulses of the Madden-Julian oscillation. Bull. Amer. Meteor. Soc., 94, 1871-1891, https://doi.org/10.1175 /BAMS-D-12-00157.1.

Yu, L., X. Jin, and R. A. Weller, 2007: Annual, seasonal, and interannual variability of air-sea heat fluxes in the Indian Ocean. J. Climate, 20, 3190-3209, https:// doi.org/10.1175/JCLI4163.1.

$\longrightarrow,-$, and $\_$, 2008. Multidecade global flux datasets from the objectively analyzed air-sea fluxes (OAFlux) project: Latent and sensible heat fluxes, ocean evaporation, and related surface meteorological variables. OAFlux Project Tech. Rep. OA-2008-01, 64 pp., http://oaflux.whoi.edu/pdfs/OAFlux _TechReport_3rd_release.pdf.

Zhang, C., 2005: Madden-Julian oscillation. Rev. Geophys., 43, RG2003, https:// doi.org/10.1029/2004RG000158.

_ - and J. Ling, 2017: Barrier effect of the Indo-Pacific Maritime Continent on the MJO: Perspectives from tracking MJO precipitation. J. Climate, 30, 3439 3459, https://doi.org/10.1175/JCLI-D-16-0614.1.

Zhang, H., H. Beggs, L. Majewski, X. H. Wang, and A. Kiss, 2016: Investigating sea surface temperature diurnal variation over the tropical warm pool using MTSAT-1R data. Remote Sens. Environ., 183, 1-12, https://doi.org/10.1016/j. rse.2016.05.002.

Zhang, N., M. Feng, H. Hendon, A. Hobday, and J. Zinke, 2017: Opposite polarities of ENSO drive distinct patterns of coral bleaching potentials in the southeast Indian Ocean. Sci. Rep., 7, 2443, https://doi.org/10.1038/s41598-017 -02688-y.

Zhou, L., and R. Murtugudde, 2020: Oceanic impacts on MJOs detouring near the Maritime Continent. J. Climate, 33, 2371-2388, https://doi.org/10.1175 IJCLI-D-19-0505.1. 